\title{
The semianalytical cloud retrieval algorithm for SCIAMACHY I. The validation
}

\author{
A. A. Kokhanovsky ${ }^{1,5}$, V. V. Rozanov ${ }^{1}$, T. Nauss ${ }^{2}$, C. Reudenbach $^{2}$, J. S. Daniel ${ }^{3}$, H. L. Miller ${ }^{3,4}$, and J. P. Burrows ${ }^{1}$ \\ ${ }^{1}$ Institute of Remote Sensing, University of Bremen, Germany \\ ${ }^{2}$ Department of Geography, University of Marburg, Germany \\ ${ }^{3}$ Aeronomy Laboratory, NOAA, Boulder, Colorado, USA \\ ${ }^{4}$ Cooperative Institute for Research in Environmental Science, University of Colorado, Boulder, Colorado, USA \\ ${ }^{5}$ Institute of Physics, 70 Skarina Avenue, Minsk, 220072, Belarus
}

Received: 2 April 2004 - Published in Atmos. Chem. Phys. Discuss.: 1 April 2005

Revised: 13 February 2006 - Accepted: 13 February 2006 - Published: 1 June 2006

\begin{abstract}
A recently developed cloud retrieval algorithm for the SCanning Imaging Absorption spectroMeter for Atmospheric CHartographY (SCIAMACHY) is briefly presented and validated using independent and well tested cloud retrieval techniques based on the look-up-table approach for MODeration resolutIon Spectrometer (MODIS) data. The results of the cloud top height retrievals using measurements in the oxygen A-band by an airborne crossed Czerny-Turner spectrograph and the Global Ozone Monitoring Experiment (GOME) instrument are compared with those obtained from airborne dual photography and retrievals using data from Along Track Scanning Radiometer (ATSR-2), respectively.
\end{abstract}

\section{Introduction}

The primary scientific objective of SCanning Imaging Absorption spectroMeter for Atmospheric CHartographY (SCIAMACHY) is to acquire data that can be used to make estimates of trace gases in the troposphere and stratosphere (Bovensmann et al., 1999). Retrievals of atmospheric trace gas amounts are performed from SCIAMACHY observations of spectral signatures in transmitted (e.g., occultation measurements) and backscattered (e.g., limb or nadir measurement modes) light. The wavelength range is from 240 till $2380 \mathrm{~nm}$. This wide spectral coverage coupled with high spectral resolution $(0.22-1.6 \mathrm{~nm}$ depending on the channel) allows for measurements of tropospheric and stratospheric abundances of a number of atmospheric constituents, with particular emphasis on the troposphere. High spatial resolution is not of primary importance for trace gas measurements, so the size of SCIAMACHY pixels is quite large (typically,

Correspondence to: A.Kokhanovsky

(alexk@iup.physik.uni-bremen.de)
$30 \times 60 \mathrm{~km}^{2}$ ). This makes the instrument not particularly suitable for the retrievals of aerosol and cloud parameters. In contrast, the Medium Resolution Imaging Spectrometer (MERIS) placed on the same space platform has a spatial resolution $0.3 \times 0.3 \mathrm{~km}^{2}$ or $1.1 \times 1.1 \mathrm{~km}^{2}$ depending on the operation mode. Thus, the top-of-atmosphere (TOA) reflectance at a single wavelength measured by SCIAMACHY corresponds roughly speaking to 20000 reflectances as obtained by MERIS. Thus, MERIS allows one to obtain highly spatially resolved maps of cloud and aerosol fields. It does not mean, however, that possibilities offered by SCIAMACHY for aerosol and cloud studies should not be explored. The superiority of SCIAMACHY is in the possibility of acquiring information over a larger spectral range and also with much higher spectral resolution as compared to MERIS. This allows for the derivation of some important characteristics of clouds (e.g., the determination of liquid water path and cloud thermodynamic state), which is hardly possible with MERIS. Also in some applications (e.g., for climate modeling) highly spatially resolved data are not required. Furthermore, clouds cover more than half of the sky at any instant globally, biasing many SCIAMACHY trace gas retrievals if cloud effects are not properly incorporated in the retrieval procedures. Therefore, we suggest that MERIS/SCIAMACHY measurements should be combined in one processing scheme to create more advanced atmospheric products (e.g., the aerosol and cloud optical thickness, trace gases vertical columns and their vertical distributions). The Advanced Along Scanning Radiometer(AATSR) on board of the ENVironmental SATellite (ENVISAT) should provide additional information (e.g., independent measurements of cloud top temperature). Unfortunately, the processing schemes for all instruments onboard ENVISAT are currently decoupled, which is mostly due to the complexity of integration of the cloud retrieval

Published by Copernicus GmbH on behalf of the European Geosciences Union. 


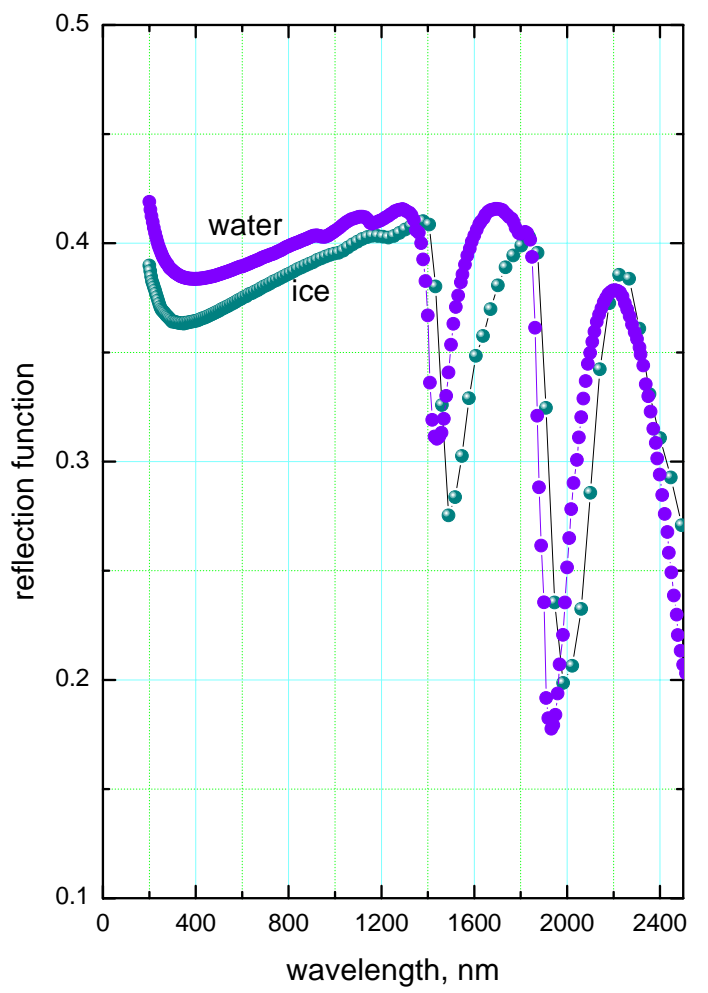

Fig. 1. The reflection function of water and ice clouds calculated as specified in the text.

algorithms for each instrument, large volumes of satellite data involved and calibration problems. We believe that the problem of integration will be solved in future missions.

All these considerations prompted us to develop the comprehensive SemiAnalytical CloUd Retrieval Algorithm (SACURA) for SCIAMACHY. The algorithm is fully described in separate publications(Kokhanovsky et al., 2003; Rozanov and Kokhanovsky, 2004). Therefore, only the outline of the technique will be presented here. The central idea of this paper is the validation of the algorithm using airborne and satellite measurements.

\section{The physical basis of SACURA}

The spectral top-of-atmosphere (TOA) reflectance $R$ in the range $240-2380 \mathrm{~nm}$ as measured by SCIAMACHY is highly dependent on the cloud optical thickness (COT), cloud droplet radius (CDR) (in near-infrared), cloud top height $(\mathrm{CTH})$ (in the oxygen A-band), and cloud thermodynamic state.

We show results of a calculation of the TOA reflection function for water and ice clouds in Fig. 1.

Calculations have been performed using the modified asymptotic equations as described by Kokhanovsky and Rozanov (2003) at the solar angle equal to 60 degrees and the nadir observation. To emphasize differences due the different complex refractive indices of liquid and solid water, the shape and size of water droplets and ice crystals have been assumed to be the same in calculations. In particular, calculations have been performed for spherical polydispersions with the effective radius of 6 microns and the gamma size distribution of particles having the coefficient of variance equal to 38 percent, which is typical for water clouds. The change of the scattering optical thickness with the wavelength was neglected, and we assumed that it is equal to 10 for all wavelengths.

The size and shape of crystals can differ significantly from those assumed in the calculations shown in Fig. 1. This can enhance differences shown in Fig. 1 even further. In particular, for the case considered, we see that the minima of reflection function for ice clouds are moved to larger wavelengths as compared to the case of water clouds. Therefore, there are regions, where the spectral dependence of reflectance is not highly correlated between ice and liquid clouds(e.g., close to $1500 \mathrm{~nm}$ and $2000 \mathrm{~nm}$, see Fig. 1). However, this may be difficult to detect due to the influence of water vapor absorption bands, which are located roughly at the same spectral regions (see Figs. 1 and 2). Therefore, one can use different slopes of spectral reflectance for ice clouds as compared to water clouds (see, e.g., the range $1550-1670 \mathrm{~nm}$ in Fig. 1). SACURA uses the cloud phase index $\alpha=R(1550 \mathrm{~nm}) / R(1670 \mathrm{~nm})$ to differentiate water/ice clouds. We found using radiative transfer calculations that this index is in the range $0.7-1.0$ for water clouds as compared to $0.5-0.7$ for ice clouds.

The cloud liquid water path $w$ and the effective radius of droplets $a_{e f}$ are retrieved from reflectances at wavelengths $412 \mathrm{~nm}$ and $1550 \mathrm{~nm}$, using a numerical technique as described by Kokhanovsky et al. (2003). Then the cloud optical thickness and the column concentration of droplets can be easily found. Note that the contribution of the gaseous absorption is negligible at these wavelengths (see Fig. 2). Due to low surface reflectance at the wavelength $412 \mathrm{~nm}$, the information on the underlying surface reflectance is not crucial for the algorithm. Also we are mostly concentrated on the case of extended optically thick clouds in which the surface contribution is further reduced. For snow-covered areas, the reflectance at $1240 \mathrm{~nm}$ is used. The snow reflectance is considerably lower at $1240 \mathrm{~nm}$ as compared to the reflectance at $412 \mathrm{~nm}$. The gaseous absorption is weak at $1240 \mathrm{~nm}$ (see Fig. 2).

The cloud top height is obtained using the fact that clouds screen oxygen in the lower atmosphere, thereby reducing the strength of the reflection function minimum close to $760 \mathrm{~nm}$ (see Fig. 2). There are about 50 measurement points inside the oxygen A-band by SCIAMACHY (Rozanov and Kokhanovsky, 2004). This allows us to estimate not only the cloud top height but also estimate the cloud geometrical thickness, the cloud base altitude, and, as a by-product, the cloud extinction coefficient. 


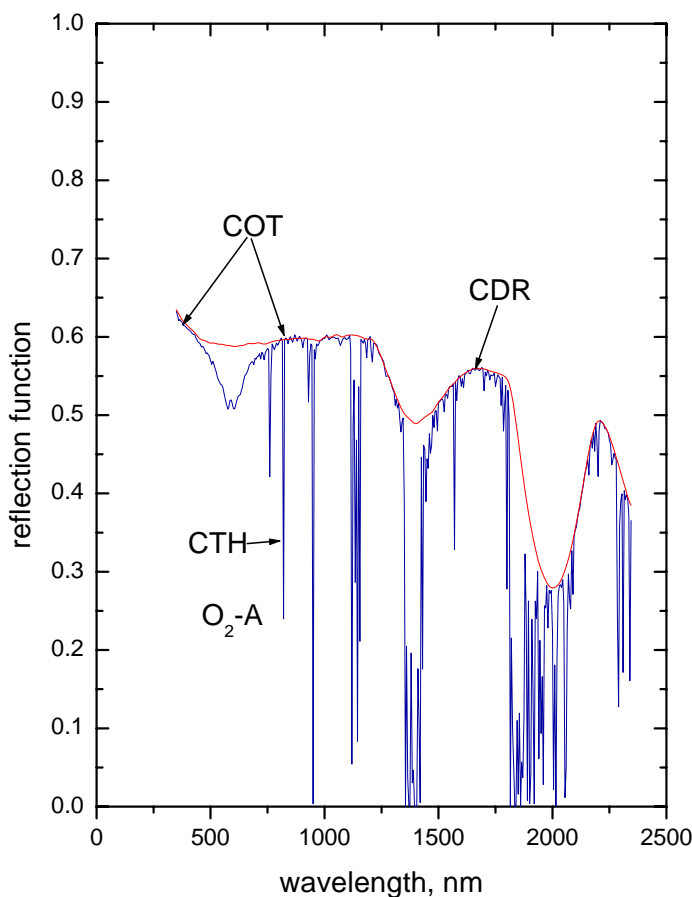

Fig. 2. The reflection function of a water cloud with and without account for the gaseous absorption calculated at the same conditions as in Fig. 1 but using the exact radiative transfer equation solution at $\tau=20$. The cloud geometrical thickness was assumed to be equal to $1 \mathrm{~km}$ and cloud top height was equal to $6 \mathrm{~km}$.

\section{Retrieval results}

\subsection{MODIS measurements}

To validate the algorithm we have applied SACURA to the MODerate resolutIon Spectrometer (MODIS) (Platnick et al., 2003) data over the North sea (Terra-MODIS granule from 11 August 2002, 10:28 UTC) and compared the results with those obtained from the well-proved and validated look-up-table (LUT) approach as described by Nakajima et al. (1995). The results of comparisons are given in Figs. 35 for the cloud optical thickness $\tau$, cloud droplet radius $a_{e f}$ and cloud liquid water path $w$. Unlike the LUT approach we are able to obtain results as quickly as the data are acquired because of computational simplicity of our technique. In particular, we used the following analytical expression for the TOA reflection function for cloudy scenes (Kokhanovsky et al., 2003).

$R=R_{\infty}-t \exp (-x-y) K(\mu) K\left(\mu_{0}\right)$.

Here $R_{\infty}$ is the reflection function of a semi-infinite cloud having the same local optical characteristics (e.g., cloud phase function and asymmetry parameter $g$, cloud single

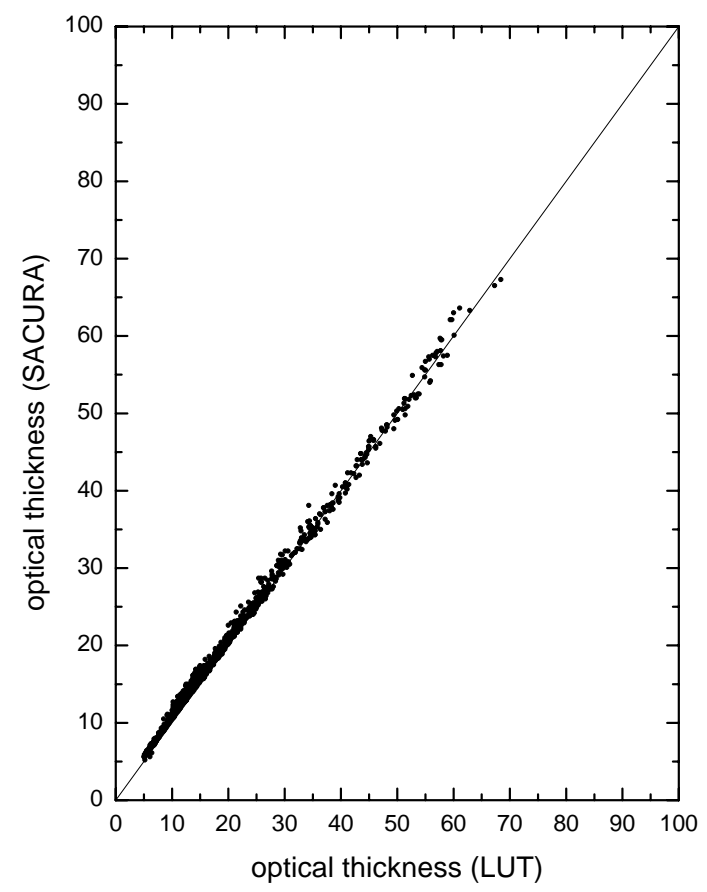

Fig. 3. The correlation between the cloud optical thicknesses retrieved using SACURA and LUT.

scattering albedo $\omega_{0}$ ) as the cloud under study, $t$ is the cloud global transmittance given as (Kokhanovsky et al., 2003)

$t=\frac{\sinh (y)}{\sinh (x+1.07 y)}$,

where $x=k \tau, y=\frac{4 k}{3(1-g)}$ and $k=\sqrt{3\left(1-\omega_{0}\right)(1-g)}$ is the diffusion exponent of the transport theory.

Values of $a_{e f}$ and $w$ do not depend on the wavelength and determine all parameters in Eq. (1) as described by Kokhanovsky et al. (2003). Therefore, taking measurements at two wavelengths, we can retrieve the pair $\left(a_{e f}, w\right)$. Then one finds the optical thickness as $3 w / 2 a_{e f} \rho$, where $\rho$ is the density of water.

It follows from Fig. 3 that the retrieved cloud optical thickness using SACURA corresponds well to the more accurate LUT approach. The wavelength used in the LUT retrieval differs from ours. In particular, we used the combination $858 / 1640 \mathrm{~nm}$ and the LUT retrievals are based on the measurements at $645 / 3700 \mathrm{~nm}$. Retrieved values of the cloud droplet radius are also in good agreement. However, retrievals of $a_{e f}$ are more biased (see Fig. 4). This may be related to the fact that different wavelengths sense different volumes of clouds. Remote sensing of clouds using the wavelength $3700 \mathrm{~nm}$ is mostly sensitive to droplets in upper parts of the cloud while the radiation with the wavelength $1600 \mathrm{~nm}$ can penetrate to deeper layers and provide information on droplets in more remote cloud areas. Note that the radius retrieved using SACURA at $1640 \mathrm{~nm}$ is slightly larger 


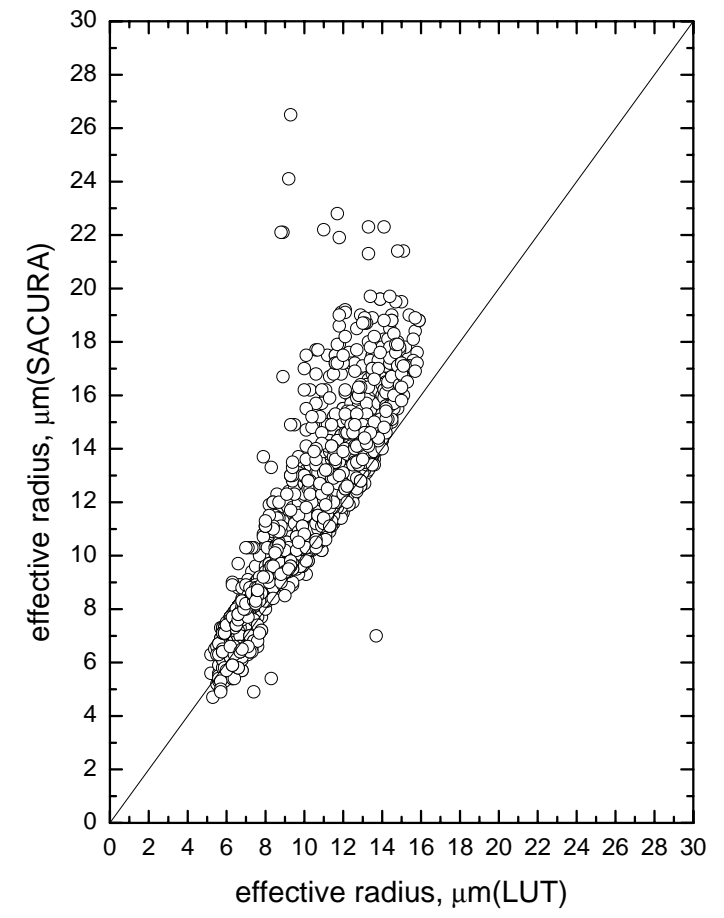

Fig. 4. The correlation between the effective radii retrieved using SACURA and LUT.

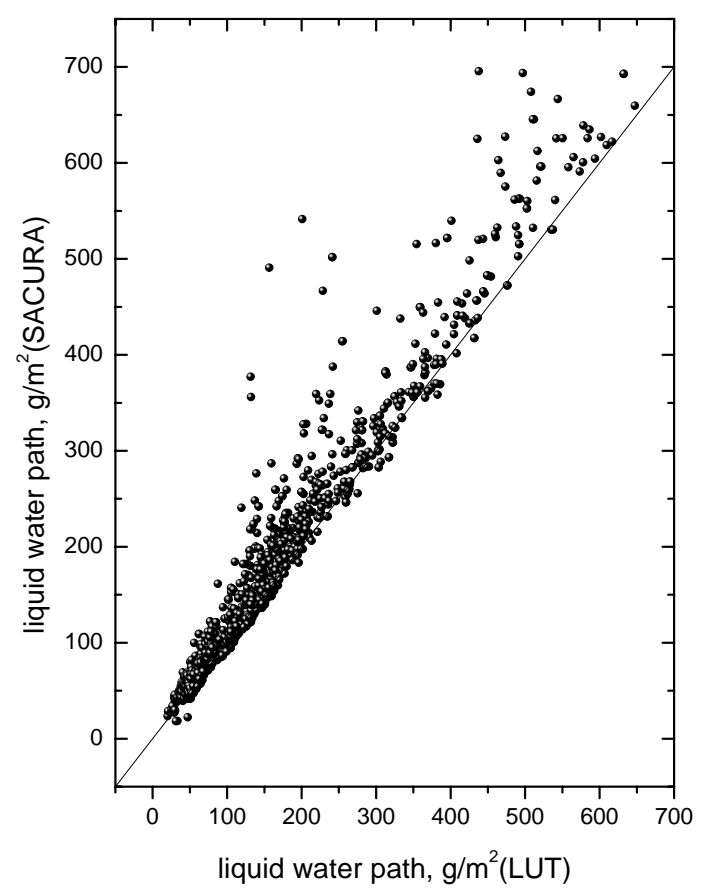

Fig. 5. The correlation between the liquid water paths retrieved using SACURA and LUT.

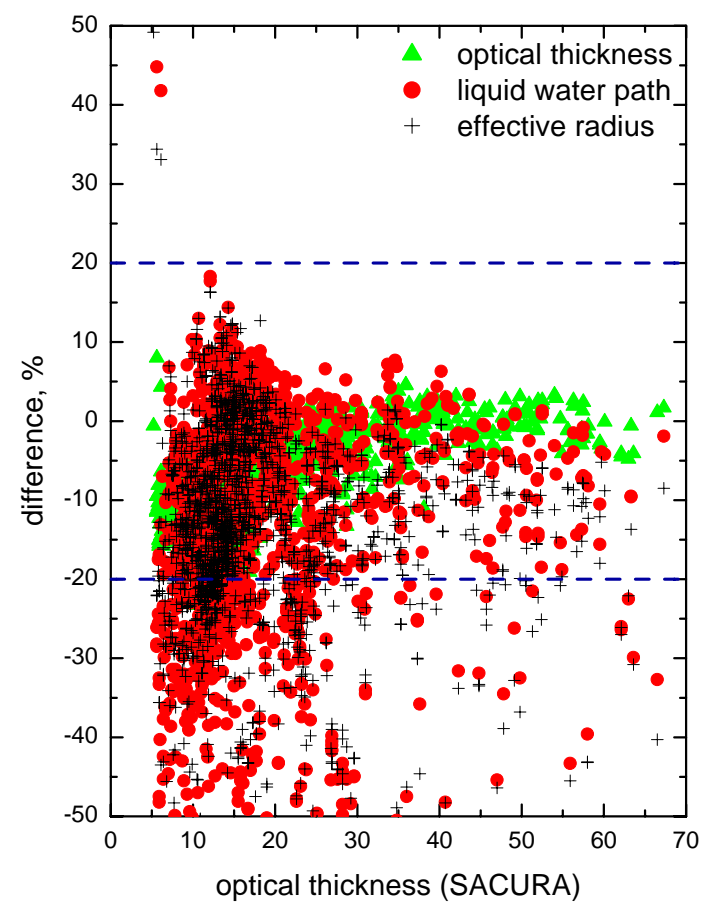

Fig. 6. The differences between cloud microphysical characteristics retrieved using different techniques.

than that which follows from the LUT approach at $3700 \mathrm{~nm}$ (see Fig. 4).

It follows from Fig. 5 that there is generally good agreement in the retrieved value of the liquid water path (especially at values $w=50-200 \mathrm{gm}^{-2}$, which are most typical for water clouds). The biases in retrievals are summarized in Fig. 6.

We see that the differences do not exceed 20 percent for most of retrievals with largest differences in the retrieved values of $a_{e f}$ and $w$ as compared to $\tau$. This may be explained by the differences in the wavelengths used as outlined above. Therefore, we conclude that SACURA gives results comparable to the LUT approach and thereby can be safely used in retrievals of cloud properties from SCIAMACHY. Relatively small differences found (see Fig. 6) should not be considered as limitations of the theory as applied to SCIAMACHY because poor spatial resolution of SCIAMACHY creates more significant biases such as those discussed above. Also the retrieval by the LUT cannot be considered as the absolute truth because of inherent problems with the adequate forward modeling of light propagation in inhomogeneous clouds. Note that we have developed a version of SACURA to be capable of dealing with partly cloudy scenes, which is essential for SCIAMACHY measurements interpretation. However, in this paper we limit ourselves to the case of completely cloudy pixels. 


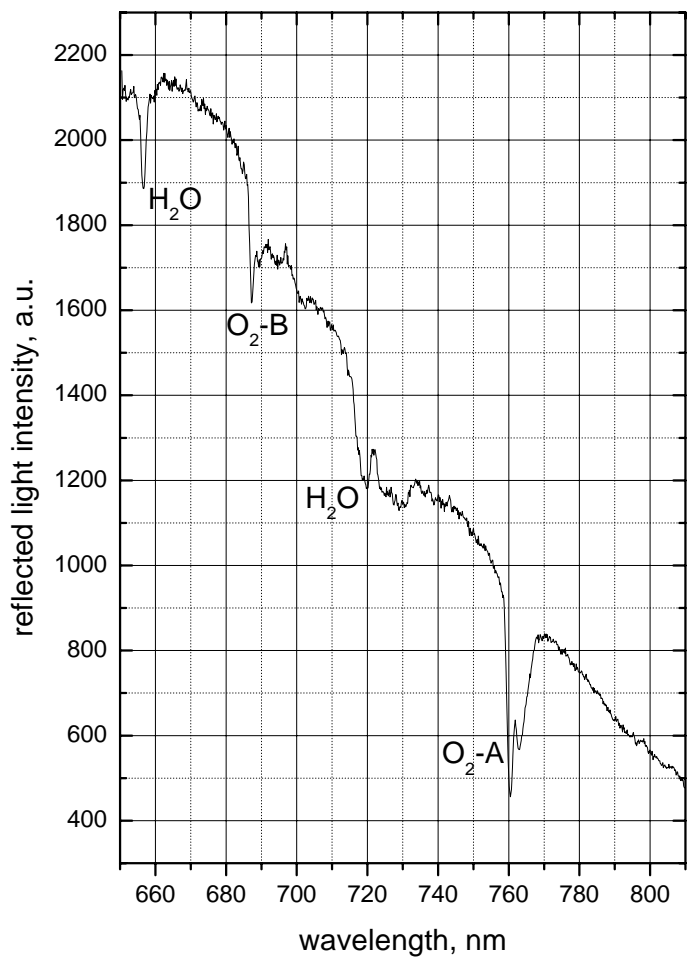

Fig. 7. The measured spectrum.

\subsection{Airborne and GOME measurements}

The MODIS does not measure TOA reflectance in the oxygen absorption bands, so our technique as applied the cloud top height determination cannot be proved using MODIS measurements in the visible or near infra-red. To validate the technique we used airborne measurements of the spectral reflectance described by Daniel et al. (2003), over the cloud system associated with Hurricane Michelle over the Gulf of Mexico on 3 November 2001. The experimental spectrum analyzed was obtained by a crossed Czerny-Turner spectrograph at 19:44 UTC and is shown in Fig. 7. The full-widthhalf-maximum wavelength resolution of this instrument is approximately $1.1 \mathrm{~nm}$. The solar zenith angle was approximately equal to 55 degrees and the observation was performed in the nadir direction from an altitude $13.7 \mathrm{~km}$.

In analyzing the raw data given in Fig. 7, we accounted for the spectral shift and smooth variations in shape (largely slope) of the measured spectrum, in a way similar to that given by Daniel et al. (2003). This is why the measured spectrum given in Fig. 8 differs from that in Fig. 7.

To compare highly resolved model calculations with spectral measurements properly, one must convolve the calculations with the numerical approximation of the instrument function, which will change the relative breadth and depth of the spectral features.

We have used the measurement of a single neon transition line as registered by the spectrometer to estimate the instru-

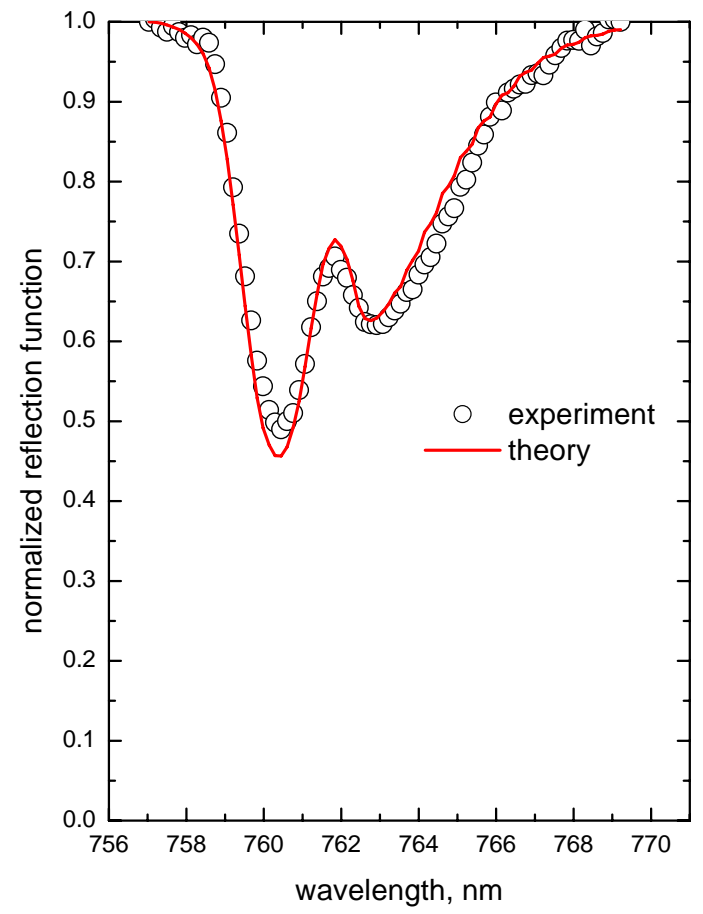

Fig. 8. The measured (circles) and fitted ( a solid line) spectra. Other parameters are specified in the text.

ment function. The high resolution model output was then convolved with this instrument function to obtain a spectrum that can be be appropriately compared with the measurement.

Because the optical thickness of the studied cloud is not known, we made a retrieval assuming a semi-infinite cloud. Crystals are often observed in clouds associated with the presence of a hurricane. Although we found that the choice of the phase function does not influence results significantly, we assumed that the phase function of the cloud could be represented by the hexagonal ice scattering model as described by Mishchenko et al. (1999). A fitted theoretical spectrum (normalized to the observed value at $756 \mathrm{~nm}$ ) is shown by a solid line in Fig. 8.

The calculation given by a solid line corresponds to a cloud top height $8.8 \mathrm{~km}$. The retrieval of Daniel at al. (2003) using their LUT approach estimate the CTH equal to $8.0 \mathrm{~km}$ within $1 \mathrm{~km}$ of our estimate. Note that the estimate of the cloud top position derived from photographs was in the range $6.2-8.0 \mathrm{~km}$.

The SACURA is extremely flexible algorithm allowing for rapid estimations of the influence of the cloud characteristics on the retrieval results. In particular, we found that the assumption of the homogeneous cloud leads to higher CTHs (by approximately $0.5 \mathrm{~km}$ ) than those retrieved for the cloud with monotonically increasing with height ice water content used in the fitting procedure (see Fig. 8).

The assumption of the ice water content profile having two maxima in the cloud reduces the estimate of the cloud top 


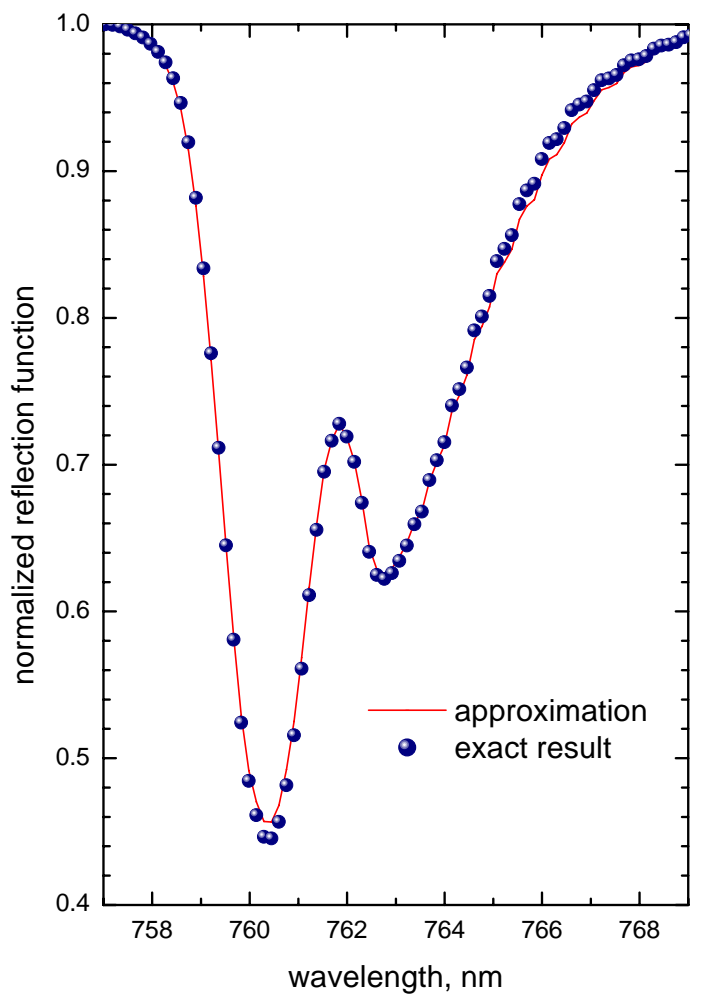

Fig. 9. The accuracy of the SACURA.

height (by approximately $0.2 \mathrm{~km}$ ), thereby moving it in the direction close to the photographic estimate and also to results of Daniel et al. (2003) although Daniel et al. (2003) did not account for ice in their retrieval.

We conclude that SACURA gives results close to the LUT approach described by Daniel et al. (2003). Its high accuracy is evident in Fig. 9, in which we compared a spectrum obtained from our approximation for the reflection function in the oxygen absorption band (Kokhanovsky and Rozanov, 2004) with exact spectrum calculated by the numerical solution of the radiative transfer equation in the oxygen absorption band. We see that differences are below 3 percent. They rarely exceed 5 percent as shown by Kokhanovsky and Rozanov (2004). Note that spectra in Fig. 9 were calculated for the same conditions as in Fig. 8 .

The case considered above was aimed to the consideration of just one spectrum. The accuracy of our technique for the cloud top pressure determination using satellite measurements can be be further probed using Fig. 10, where we show the comparison of SACURA cloud top pressure $p$ retrievals using Global Ozone Monitoring Experiment (GOME) measurements in the oxygen A-band with retrievals of $p$ from ATSR-2 infrared data(Watts et al., 1998). Note that both GOME and ATSR-2 are on the same space platform. The retrieval shown in Fig. 10 is based on GOME measurements for orbit 80324174 of the Earth Remote Sensing Satellite (ERS2) over Pacific ocean on 28 March 1998. Joiner et al. (2003)

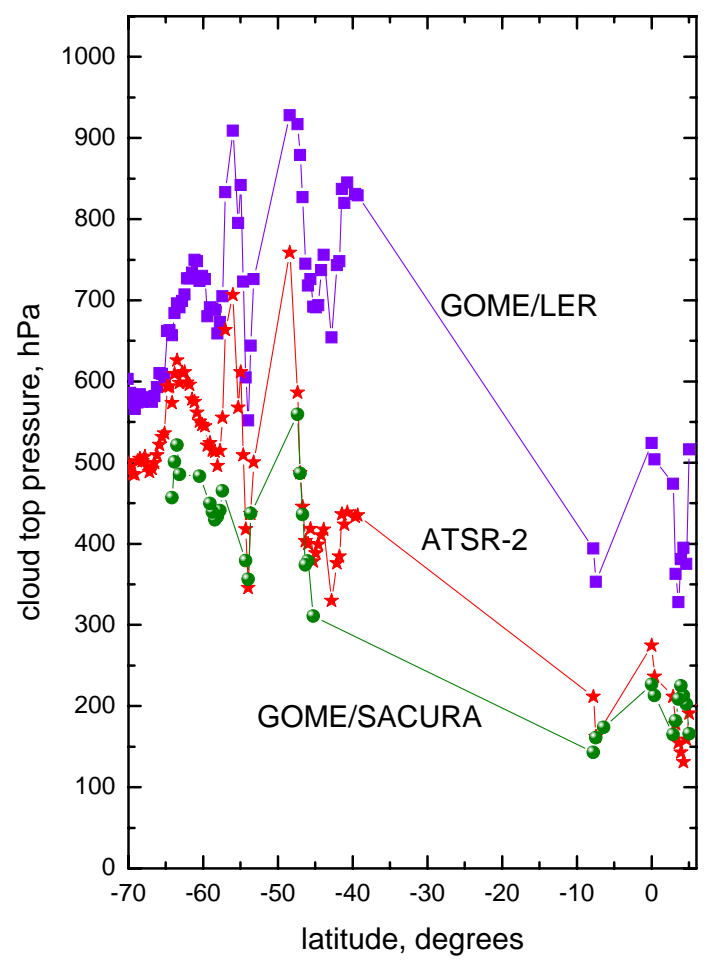

Fig. 10. The comparison with retrievals using infrared measurements performed by ATSR-2 data.

have retrieved the Lambertian - equivalent pressure $p_{l}$ for the same orbit. We also show this result in Fig. 10 as a reference. However, note that $p_{l}$ differs from the cloud top pressure retrieved in our paper by definition.

The spatial resolution of ATSR-2 is $1 \mathrm{~km}^{2}$ while for GOME it is $40 \times 320 \mathrm{~km}^{2}$ or $40 \times 80 \mathrm{~km}^{2}$, depending on the measurement mode. The problem with the different spatial resolution of these instruments was addressed by averaging ATSR-2 data onto the $40 \times 80 \mathrm{~km}^{2}$ GOME pixel size. Only $40 \times 80 \mathrm{~km}^{2}$ pixels of GOME have been considered. In particular, we see that the application of SACURA to GOME data gives results close to the ATSR-2 retrievals.

\section{Conclusions}

Our comparisons show that SACURA is an accurate and flexible tool to study cloud properties. The SACURA - derived values of the cloud optical thickness, the effective radius of droplets, and the liquid water path are in a good agreement with correspondent results obtained using Look-UpTable approach (see Figs. 3-5). More details on applications of SACURA to MODIS data and comparisons with the LUT approach for clouds over both land and ocean are given by Nauss et al. (2005).

In addition, we have checked the accuracy of the cloud top height as derived using SACURA $O_{2}$ spectrometry with 
LUT approach of Daniel et al. (2003). It was found that differences in the derived CTHs depend on assumed cloud properties (e.g., the vertical structure of clouds, the presence of the ice phase, etc.). However, they do not exceed $1 \mathrm{~km}$. Also SACURA as applied to GOME data gives cloud top heights close to those obtained from infrared ATSR-2 measurements over ocean, where the uncertainties related to generally unknown contribution from the surface can be neglected.

Acknowledgements. MODIS data have been provided by NASA via Marburg Satellite Station. This work has been funded by the BMBF via GSF/PT-UKF and by the DFG BU 688/8-1 and BMBF 07 GWK 04 Projects. We are grateful to J. Joiner (NASA) for providing data for Fig. 10 (ATSR-2 and GOME/LER) in a tabular form. European Space Agency, the UK Natural Environment Research Council and the Rutherford Appleton Laboratory are acknowledged for their support in supplying ATSR-2 and GOME data.

Edited by: U. Platt

\section{References}

Bovensmann, H., Burrows, J. P., Buchwitz, M., Frerick, J., Noël, S., Rozanov, V. V., Chance, K. V., and Goede, A. P. H.: SCIAMACHY: Mission objectives and measurement methods, J. Atmos. Sci., 56, 127-150, 1999.

Daniel J. S., Solomon, S., Miller, H. L., Langford, A. O., Portmann, R. W., and Eubank, C. S.: Retrieving cloud information from passive measurements of solar radiation absorbed by molecular oxygen and $\mathrm{O}_{2}-\mathrm{O}_{2}$, J. Geophys. Res., 108(D16), 4515, doi:10.1029/2002JD002994, 2003.

Joiner, J., Vasilkov, A. P., Flittner, D. E., Gleason, J. F., and Bhartia, P. K.: Retrieval of cloud pressure and oceanic chlorophyll content using Raman scattering in GOME ultraviolet spectra, J. Geophys. Res., 109, D01109, doi:10.1029/2003JD003698, 2004.
Kokhanovsky, A. A. and Rozanov, V. V.: The reflection function of optically thick weakly absorbing turbid layers: a simple approximation, J. Quant. Spectr. Rad. Transfer, 77, 165-175, 2003.

Kokhanovsky, A. A., Rozanov, V. V., Zege, E. P., Bovensmann, H., and Burrows, J. P.: A semianalytical cloud retrieval algorithm using backscattered radiation in $0.4-2.4 \mu \mathrm{m}$ spectral region, J. Geophys. Res., 108(D1), 4008, doi:10.1029/2001JD001543, 2003.

Mishchenko, M. I., Dlugach, J. M., Yanovitskij, E. G., and Zakharova, N. T.: Bidirectional reflectance of flat, optically thick particulate layers: an efficient radiative transfer solution and applicatioins to snow and soil surfaces, J. Quant. Spectr. Rad. Transfer, 63, 409-432, 1999.

Rozanov, V. V. and Kokhanovsky, A. A.: Semianalytical Cloud retrieval algorithm as applied to the cloud top altitude and the cloud geometrical thickness determination from top-of-atmosphere reflectance measurements in the oxygen A band, J. Geophys. Res., 109, D05202, doi:10.1029/2003JD004104, 2004.

Nakajima, T. Y. and Nakajima, T.: Wide-area determination of cloud microphysical properties from NOAA AVHRR measurements for FIRE and ASTEX regions, J. Atmos. Sci., 52, 40434059, 1995.

Nauss, T., Kokhanovsky, A. A., Nakajima, T. Y., Reudenbach, C., Bendix, J.: The intercomparison of cloud retrieval algorithms, Atmos. Res., 78, 46-78, 2005.

Platnick, S., King, M. D., Ackerman, S. A., Menzel, W. P., Baum, B. A., Riedi, J. C., and Frey, R. A.: The MODIS cloud products: Algorithms and examples from Terra, IEEE Trans. on Geosci. and Rem. Sens., 41, 459-473, 2003.

Watts, P. D., Mutlow, C. T., Baran, A. J., Zavody, A. M.: Semianalytical study on cloud properties derived from Meteosat Second Generation observations, ITT no. 97/181, 344 pp., EUMETSAT, Darmstadt, Germany (see http://www.eumesat.de), 1998. 